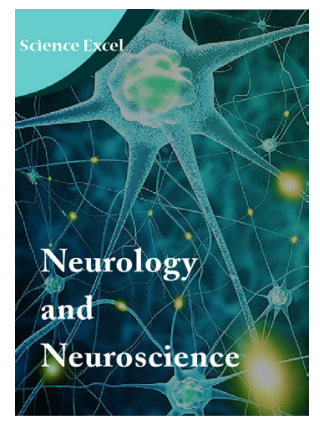

\section{Correspondence}

Ioanna Alexandratou

Department of Neurology, Evangelismos Hospital, Ipsilantou 45-47, 10667, Athens, Greece

- Received Date: 27 Jan 2020;

- Accepted Date: 07 Mar 2020;

- Publication Date: 18 Mar 2020.

Copyright

(c) 2020 Science Excel. This is an openaccess article distributed under the terms of the Creative Commons Attribution 4.0 International license.

\title{
Monocular pendular nystagmus in a patient with a dolichoectatic basilar artery
}

\section{loanna Alexandratou ${ }^{*}$, Chara Zachariadi ${ }^{1}$, Vasileios K Katsaros ${ }^{2}$ and Stylianos Gatzonis $^{3}$}

'Department of Neurology, Evangelismos Hospital, Ipsilantou 45-47, 10667, Athens, Greece

2Department of Advanced Imaging Modalities, General Anti-Cancer and Oncological Hospital of Athens "St. Savvas", Leof. Alexandras 119, 11475, Athens, Greece

${ }^{3}$ Neurosurgical Department of Epilepsy, Evangelismos Hospital, Ipsilantou 45-47, 10667, Athens, Greece

\begin{abstract}
We present the case of a patient with the symptom of oscillopsia for the past six months. The neurological examination revealed a monocular horizontal pendular nystagmus in the left eye, present in all directions of gaze, while the remainder of neurological examination was normal. MRI brain scan revealed a dolichoectatic basilar artery causing a mild compression to the left part of the pontomedullary junction.
\end{abstract}

\section{Introduction}

EVertebrobasilar dolichoectasia (VBD) is a rare dilative arteriopathy defined as elongation or widening of the intracranial vertebral and/or basilar arteries [1].The prevalence ranges from $0.06 \%$ to $5.8 \%$ [2]. The majority of VBDs are asymptomatic but it can also present with symptoms due to: 1 ) compression of brainstem, 2) direct compression of cranial nerve, 3) ischemia of vertebrobasilar territory, 4) rupture of vessel, and 5) hydrocephalus [3-5]. VBD has also been linked with rare ocular movement disorders, as the downbeat nystagmus [6-8]. Pendular nystagmus is another major type of nystagmus. Pendular nystagmus is a sinusoidal oscillation without fast phases[9]. The waveform of pendular nystagmus may occur in any direction; it can be torsional, horizontal, vertical, or a combination of these, resulting in circular, oblique, or elliptical trajectories. It may be different in the two eyes, sometimes even monocular [10].Most patients with acquired pendular nystagmus have multiple sclerosis [11]. Less commonly it follows strokes, encephalitis, or vascular malformations in the cerebellum or brainstem [12-13] and occasionally tumors [14]. Rare causes include chronic toluene encephalopathy [15], unusual familial syndromes [16], and orbital myositis [17].

We present the rare case of an acquired monocular pendular nystagmus in a patient with VBD.

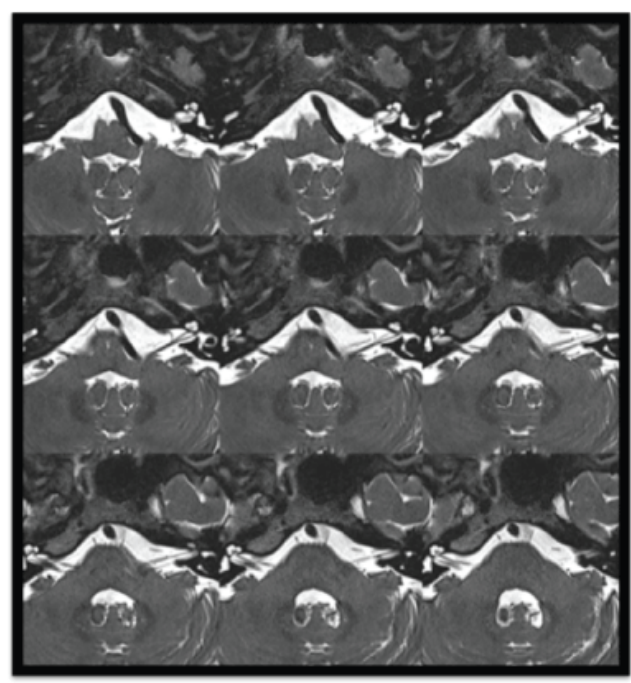

Figure 1. Dolichoectatic basilar artery causing displacement and pressure effects on the pontomedullary junction and left pons.

Citation: Alexandratou I, Zachariadi C, Katsaros VK, et al. Monocular pendular nystagmus in a patient with a dolichoectatic basilar artery. Neurol Neurosci. 2020;1(1):1-2 


\section{Case Report}

A 60-year-old woman presented in our outpatient clinic, acclaiming that for the past six months, she has the strange sensation of spinning when she closes only her right eye and looks with her left eye. Specifically, she described the feeling of oscillopsia during reading. She had a medical history of panic disorders and she took no medication. No history of chronic alcoholic exposure or lithium intoxication was reported. The family history was free. She claimed no double vision, headache, weakness, or any other symptoms. On examination, she appeared well and her blood pressure was $150 / 100 \mathrm{~mm} \mathrm{Hg}$; heart rate, $80 / \mathrm{min}$; and respiratory rate, $14 / \mathrm{min}$. On ocular examination, visual acuity was 20/20 in both eyes. Anterior segment and fundus examination were unremarkable. A monocular horizontal pendular nystagmus in the left eye was noted. There was no change in rate and character of the nystagmus and it occurred in any direction. In the right eye, no pathological ocular movements were detected. Extraocular muscles movements, saccadic velocity, and smooth pursuit eye movements were within normal limit. Cranial nerve function was otherwise normal. The remainder of the neurological examination revealed normal muscle tone, strength, reflexes and gait. In order to exclude an epileptic monocular nystagmus, an electroencephalogram (EEG) was performed. It was characterized by an admixture of beta and alpha frequency range. No epileptiform discharges were recorded. Magnetic resonance imaging (MRI) of the brain revealed dolichoectatic basilar artery causing displacement and pressure effects on the pontomedullary junction and pons left, near the VII and VIII nerve nucleus, as well as on the ipsilateral VI and VII nerves from the pre-pontine cistern till the level of the cerebellopontine angle. Supratentorial cerebral hemispheres appeared unremarkable. No restricted diffusion on diffusion-weighted imaging (DWI) was depicted (Figure 1).

The patient was examined in our outpatient clinic on a follow-up basis for one year with no changes in her neurological examination. The symptoms of oscillopsia remained, but she refused on taking any medication.

\section{Discussion}

ANystagmus is a rhythmic regular oscillation of the eyes. It may consist of alternating phases of a slow drift in one direction with a corrective quick "jerk" in the opposite direction, or of slow, sinusoidal, pendular oscillation [18].Research into mechanisms that normally control eye movements has led to a better understanding of the pathogenesis of different types of acquired nystagmus [19].

There are several articles in literature reporting cases of monocular pendular nystagmus as a rather bizarre finding in neurological examination. Acquired pendular monocular nystagmus often occurs in association with disorders affecting the visual system, such as multiple sclerosis [20]. In Brodsky et al, a case of a 9-year-old girl with chiasmal glioma and longstanding monocular nystagmus is reported [21]. The Heimann-Bielschowsky phenomenon (HBP) is an unusual form of monocular vertical pendular nystagmus and is usually asymptomatic. It always occurs in an eye with longstanding, profound visual loss. Nguyen et al., reported a series of patients with HBP and mentioned how often these cases are under diagnosed [22]. In addition to the above, there are a series of articles reporting monocular nystagmus as a clinical finding of epileptic phenomena [23-25]. Schulz et al presented the case of a patient with epileptic monocular nystagmus and ictal diplopia who became seizure free after resection of a right frontal focal dysplasia (FCD)[26].

In our case, the patient visited our outpatient clinic due to the feeling of oscillopsia for the past six months. The only clinical finding in the neurological examination was a horizontal monocular pendular nystagmus in the left eye. EEG was normal. Except the dolichoectatic basilar artery no other abnormalities were identified in the MRI.

Radiographic confirmation of displacement and pressure effects on the pontomedullary junction and left pons, near the VII and VIII nerve nucleus, provides the most plausible mechanism for monocular nystagmus in this setting. Whether an actual cause-and-effect relationship exists between dolichoectasia of the basilar artery and monocular nystagmus remains speculative. We, however, report this case of a patient with monocular nystagmus and VBD as a sufficient mechanism.

\section{Conclusion}

EThis is a rare case of a patient with vertebrobasilar dolichoectasia and a monocular pendular nystagmus as a clinical event. This finding is not conclusive enough; however, we suggest that dolichoectatic vertebrobasilar artery could be associated with a proportion of cases of monocular nystagmus of undetermined cause.

\section{References}

1. Dziewasa R, Freund M, Ludemann P, Muller M, Ritter M, Droste DW, et al. Treatment options in vertebrobasilar dolichoectasia - case report and review of the literature. Eur Neurol. 2003; 49(4):245-247.

2. Resta M, Gentile MA, Di Cuonzo F, Vinjau E, Brindicci D, Carella A. Clinicalangiographic correlations in 132 patients with megadolicho-vertebrobasilar anomaly. Neuroradiology. 1984; 26(3):213-216.

3. Ekbom K, Greitz T, Kugelberg E. Hydrocephalus due to ectasia of the basilar artery J Neurol Sci. 1969;8(3):465-477.

4. Milandre L, Bonnefoi B, Pestre P, Pellissier JF, Grisoli F, Khalil R. Vertebrobasilar arterial dolichoectasia. Complications and prognosis. Rev Neurol (Paris) 1991 147(11):714-722.

5. Passero S, Filosomi G. Posterior circulation infarcts in patients with vertebrobasilar dolichoectasia. Stroke. 1998;29(3):653-659.

6. Himi T, Kataura A, Tokuda S, Sumi Y, Kamiyama K, Shitamichi M. Downbeat nystagmus with compression of the medulla oblongata by the dolichoectatic vertebral arteries. Am J Otol. 1995; 16(3):377-381.

7. Jacobson DM, Corbett JJ. Downbeat nystagmus associated with dolichoectasia of the vertebrobasilar artery. Arch Neurol. 1989; 46(9):1005-10.

8. Kobayashi T, Ogawa A, Kameyama M, Uenohara H, Yoshimoto T. Chiari. Malformation with compression of the medulla oblongata by the vertebral arteries. J Neurosurg. 1992; 77(2):307-309.

9. Kang S, Shaikh AG. Acquired pendular nystagmus. J Neurol Sci. 2017 Apr 15;375:817.

10. Gresty MA, Ell JJ, Findley LJ. Acquired pendular nystagmus: its characteristics, localising value and pathophysiology. J Neurol Neurosurg Psychiatry. 1982;45(5):431

11. Aschoff JC, Conrad B, Kornhuber HH. Acquired pendular nystagmus with oscillopsia in multiple sclerosis: a sign of cerebellar nuclei disease. J Neurol Neurosurg Psychiatry. 1974;37(5):570.

12. Rota E, Morelli N, Immovilli P, Magnifico F, Crisi G, Guidetti D. Acquired pendular nystagmus from cerebellar nodulus acute ischemic lesion. Neurology. 2012 Aug;79(8):832.

13. Schievink WI, Piepgras DG, Earnest F 4th, Gordon H. Spontaneous carotidcavernous fistulae in Ehlers-Danlos syndrome Type IV. Case report.J Neurosurg. 1991;74(6):991.

14. Işikay S. Pendular Nystagmus Associated With Cerebral Pylomixoid Astrocytoma. Pediatr Neurol. 2016:61:117.

15. Maas EF, Ashe J, Spiegel P, Zee DS, Leigh RJ. Acquired pendular nystagmus in toluene addiction. Neurology. 1991;41(2 ( Pt 1)):282

16. Bassani R, Pareyson D, D'Incerti L, Di Bella D, Taroni F, Salsano E. Pendular nystagmus in hypomyelinating leukodystrophy. J Clin Neurosci. 2013; 20(10):1443-5.

17. Goldberg RT. Vertical pendular nystagmus in chronic myositis of medial and lateral rectus. Ann Ophthalmol. 1978;10(12):1697.

18. Rucker JC. Nystagmus and Saccadic Intrusions. Continuum (MinneapMinn). 2019; 25(5):1376-1400.

19. Käsmann-Kellner B. [Nystagmus. Clinical characteristics and therapeutic options] Ophthalmologe. 2016 Mar;113(3):253-71; quiz 272-3.

20. Jung I, Kim SH, Kim HJ, Choi JY, Kim JS. Modulation of acquired monocular pendular nystagmus in multiple sclerosis: A modeling approach. Prog Brain Res.2019;249:227-234

21. Brodsky MC, Keating GF. Chiasmal glioma in spasmus nutans: a cautionary note. Neuroophthalmol. 2014; 34(3):274-5.

22. Nguyen A, Borruat FX. The Heimann-Bielschowsky Phenomenon: A Retrospective Case Series and Literature Review. Klin Monbl Augenheilkd. 2019; 236(4):438-441.

23. Grant AC, Jain V, Bose S. Epileptic monocular nystagmus. Neurology. 2002;59(9):1438-41.

24. Kellinghaus $C$, Loddenkemper T, Lüders HO. Epileptic monocular nystagmus Neurology. 2003;61(1):145-7; author reply 147.

25. Jacome DE, FitzGerald R. Monocular ictal nystagmus. Arch Neurol. 1982;39(10):6536.

26. Schulz R, Tomka-Hoffmeister M, Woermann FG, Hoppe M, Schittkowski MP, Ebner A, et al. Epileptic monocular nystagmus and ictal diplopia as cortical and subcortical dysfunction.Epilepsy Behav Case Rep. 2013;1:89-91. 